\title{
Professor André Jacquemin: Reconhecimento a sua Trajetória Profissional
}

\author{
Sonia Regina Pasian ${ }^{1}$ \\ ${ }^{1}$ Universidade de São Paulo, SP, Brasil.
}

\author{
Erika Tiemi Kato Okino ${ }^{1}$ \\ ${ }^{1}$ Universidade de São Paulo, SP, Brasil.
}

Resumo: A história da Psicologia no Brasil coleciona diferentes e corajosos pesquisadores, dentre os quais o presente trabalho ilustra a trajetória profissional do Professor André Jacquemin. Nascido na Bélgica, graduado em Psicologia na Universidade Católica de Louvain (Bélgica), aceitou o convite, em 1967, para trabalhar no Brasil na Universidade de São Paulo, onde atuou em diferentes funções enquanto educador, gestor e pesquisador até 2001, quando se afastou do trabalho por motivos de saúde, falecendo em 2017. Este trabalho procura historiar e dar visibilidade a seu percurso profissional de modo a deixar registradas suas relevantes contribuições para a Psicologia do Brasil, em especial no campo da avaliação psicológica e dos métodos projetivos.

Palavras-chave: Avaliação Psicológica, Métodos Projetivos, ASBRo.

\section{Professor André Jacquemin: Recognition of his Professional Trajectory}

Abstract: The history of Psychology in Brazil collects different and courageous researchers, among which the present work illustrates the professional trajectory of Professor André Jacquemin. Born in Belgium, graduated in Psychology from the Catholic University of Louvain (Belgium), he accepted the invitation in 1967 to work in Brazil at the University of São Paulo, where he worked as an educator, manager and researcher until 2001, when he left of work for health reasons, dying in 2017. This work seeks to historicize and give visibility to his professional career in order to register his relevant contributions to the Psychology of Brazil, especially in the field of psychological assessment and projective methods.

Keywords: Psychological Assessment, Projective Methods, ASBRo.

\section{Profesor André Jacquemin: Reconocimiento a su Trayectoria Profesional}

Resumen: La historia de la Psicología en Brasil colecciona diferentes y valientes investigadores, entre los cuales el presente trabajo ilustra la trayectoria profesional del Profesor André Jacquemin. Nacido en Bélgica, graduado en Psicología en la Universidad Católica de Louvain (Bélgica), aceptó la invitación, en 1967, para trabajar en Brasil en la Universidad de São Paulo, donde actuó en diferentes funciones como educador, gestor e investigador hasta 2001, cuando se alejó del trabajo por motivos de salud, falleciendo en 2017. Este trabajo busca historiar y dar visibilidad a su recorrido profesional de modo a dejar registradas sus relevantes contribuciones a la Psicología de Brasil, en especial en el campo de la evaluación psicológica y de los métodos proyectivos.

Palabras clave: Evaluación Psicológica, Métodos Proyectivos, ASBRo. 


\section{Introdução}

O teor desse trabalho permite algumas licenças formais para tornar exequível seu objetivo: historiar, ainda que brevemente, e homenagear o percurso profissional do Professor André Jacquemin. Nascido na Bélgica, em Baranzy, em 7 de setembro de 1942, trabalhou na Faculdade de Filosofia, Ciências e Letras de Ribeirão Preto da Universidade de São Paulo (FFCLRP/USP) desde 1967 até o ano de 2001, quando se afastou por motivos de saúde. Faleceu em $1^{\circ}$ de setembro de 2017, após 16 anos de intensivos cuidados de saúde realizados por seus dedicados familiares. Naturalizou-se cidadão brasileiro, construindo aqui sua carreira, seus vínculos pessoais e sociais.

Nesse profícuo percurso de vida, temos a declarar que histórias compartilhadas geralmente aproximam e fortalecem os vínculos entre pessoas, podendo oferecer uma sensação de agradável aconchego. $\mathrm{O}$ reencontro com pessoas que fizeram parte da nossa história reafirma e fortalece a composição da própria existência. A nostalgia é elemento sempre presente nos encontros, reencontros e a acontecimentos da infância, adolescência e adultez. Ela integra nossos repertórios de vida e de recordações, objeto desse atual trabalho de homenagem ao Professor André Jacquemin.

As habilidades e traquejos sociais são arduamente exercitados desde a infância e a adolescência, por meio das brincadeiras e travessuras, das paixões e decepções, dos anseios e temores até que nos deparamos com as exigências do mundo adulto. Nesse processo de desenvolvimento, a Escola se configura como um espaço que nos acolhe e nos oferece muitas das oportunidades para o exercício social dessas habilidades e experiências. E na coordenação desse novo espaço, encontramos sempre a emblemática figura do Professor. Como já dizia Rubem Alves, na primeira edição do seu livro "A alegria de ensinar", que "o negócio do professor é ensinar felicidade”. Em suas palavras:

O mestre nasce da exuberância da felicidade. E, por isso mesmo, quando perguntado sobre a sua profissão, os professores deveriam ter a coragem para dar a absurda resposta: "sou um pastor da alegria..." Mas, é claro, somente os seus alunos poderão atestar a verdade de sua declaração... (Alves, 1994, p. 12).

Em sintonia com esse pensamento, Trinca (2001) concordou que infundir alegria e entusiasmo nos jovens alunos seria uma das funções (nada fáceis) do professor. Apresentados esses princípios, chegamos ao Professor André, assim chamado pela maioria daqueles que o conheceram. Sempre lhe foi possível entusiasmar e inspirar jovens adultos, a partir da genuína satisfação que suas pesquisas lhe proporcionavam. Suas aulas eram permeadas pela emoção em compartilhar descobertas com seus alunos e a comunidade (acadêmica ou não), que sempre o ouviam com muito interesse e admiração.

Duas características fundamentais para que alguém possa ser um bom professor são amplamente destacadas por Mário Sérgio Cortella (comunicação pessoal): vontade de aprender e humildade em reconhecer que é preciso aprender. Palavras sábias aplicadas à complexidade do contexto educacional, que nos inspiram e nos auxiliam nessa homenagem a André Jacquemin, um professor querido e admirado por muitos.

Nesta homenagem que fazemos a ele, buscamos compartilhar a história de um "velho conhecido". As ricas experiências de convívio com o Professor André aconteciam durante suas aulas, por meio de seus artigos, em encontros gourmets, como tanto apreciava, e hoje nos soam como momentos aconchegantes de saudade. Sua trajetória nos permite afirmar que André Jacquemin foi um dos grandes colaboradores na história da Psicologia e para a área da Avaliação Psicológica no Brasil, em especial, a dos métodos projetivos. Professor de personalidade inteligente e acolhedora, amava o Brasil e a sua profissão. E foi com paixão pelo conhecimento que ele conduziu toda a sua carreira como educador, confirmando que "só é um bom ensinante quem for um bom aprendente” (Mário Cortella, comunicação pessoal).

$\mathrm{Na}$ esperança de testemunharmos esse histórico de Professor e psicólogo apaixonado pela profissão, passamos a descrever passos do percurso profissional de André Jacquemin.

\section{Trajetória docente e administrativa}

O Professor André iniciou seu percurso profissional na Faculté de Psychologie et des Sciences de Éducation da Université Catholique de Louvain (UCL - Bélgica), onde se graduou em Psicologia no ano de 1964, com distinção. Essa honraria universitária ("distinção na graduação") conferiu destaque suficiente para ser convidado a trabalhar naquela Universidade, como assistente do Professor Paul Franckard, no Centro de Orientação Profissional da UCL, em Louvain (Bélgica), nos anos de 1965-1966. Atendia casos de orientação 
profissional e aconselhamento. Aprofundou-se nas técnicas de entrevista e de diagnóstico, especialmente o Psicodiagnóstico de Rorschach, sempre realizando pesquisas nesse campo. Seu desempenho, conduta pessoal e profissional o fizeram ser conhecido como o "belga de bom senso", assim chamado por colegas, em especial pelo amigo Paul Stephaneck (in memorian).

Sua atuação profissional, permeada por atitude curiosa e investigativa para com a sua realidade, além de traços empreendedores, rendeu convite adicional para atuar profissionalmente. O novo convite foi formalizado pelo renomado Professor Lucien Lison, professor belga que em 1964 já trabalhava no Brasil, na Faculdade de Medicina de Ribeirão Preto da Universidade de São Paulo (FMRP-USP). Naquela época, o professor Lison trabalhou como atuante colaborador para a fundação e desenvolvimento da Faculdade de Filosofia, Ciências e Letras de Ribeirão Preto da Universidade de São Paulo (FFCLRP-USP), recém-criada em março de 1964.

Apesar de muitos apelos pessoais e profissionais que favoreciam sua permanência na Bélgica, em 7 de janeiro de 1967, o Professor André, acompanhado por sua esposa Josette Balfroid, chegou ao Brasil com a missão de auxiliar a criação e desenvolvimento do Curso de Psicologia do Departamento de Psicologia da FFCLRP-USP. Sua tarefa na época era lecionar disciplinas profissionalizantes para o curso de Formação de Psicólogos, em implantação na referida Unidade USP. Desde então, sua cultura europeia, seu comprometimento ético e científico, sempre acompanhados por sua sensibilidade e energia empreendedora, fizeram-se presentes em sua trajetória pessoal e profissional. Nessa época foi fundador do Centro de Psicologia Aplicada (CPA) na FFCLRP-USP, estruturando e ofertando os primeiros estágios profissionalizantes daquele Curso de Psicologia.

O contexto de sua chegada ao trabalho no Brasil e na FFCLRP-USP constituiu um grande desafio, de caráter pessoal e profissional. Seu amigo Jacques Draime, colega na UCL, assim o descreveu: "André era um homem alto, digno, grande por natureza e grande também por sua personalidade. André era um líder! Sempre teve muita iniciativa e liderou grandes projetos!" (Okino, Pasian, Petean, \& Santos, 2001, p. 50).

Em 1973 defendeu Tese de Doutoramento em Ciências pela Universidade de São Paulo, apresentando o trabalho: "O Teste de Rorschach em crianças brasileiras - pesquisa e atlas". Publicou, em 1976, um livro sobre sua experiência com o Psicodiagnóstico de Rorschach (Jacquemin, 1976), retratando esses parâmetros normativos da Escola Francesa desse método projetivo. Entre 1979-1981 realizou estágio de Pós-Doutorado na Université Catholique de Louvain (Bélgica) de onde trouxe as inovações no campo da Orientação Profissional. Foi assim, responsável pela introdução e adaptação do Teste de Fotos de Profissões (BBT), de Martin Achtnich, no contexto brasileiro, criando o BBT-Br. Em 1981 realizou seu concurso de Livre-Docência na FFCLRP-USP e, já em 1983, tornou-se Professor Titular da mesma Unidade USP, onde permaneceu até seu afastamento por motivos de saúde (em 2001).

O Professor André seguiu os apelos de sua vocação científica e administrativa e teve uma carreira extremamente rica e brilhante que o levou à posição de Professor Titular e a Diretor da FFCLRP-USP em 1988. Nessa trajetória administrativa, exerceu funções de reconhecida e marcante contribuição na FFCLRP-USP: Vice-Chefe do Departamento de Psicologia (1980-1982), Chefe do Departamento de Psicologia (1982-1986), Vice-Diretor (1986-1988) e Diretor da FFCLRP-USP (1988-1992). Além disso, exerceu a função de Representante da Congregação da FFCLRP-USP junto ao Conselho Administrativo do Campus USP de Ribeirão Preto (1981-1983), Membro da Câmara de Pesquisa e Avaliação do Conselho de Ensino, Pesquisa e Extensão de Serviços à Comunidade da USP (1985-1986) e Membro da Comissão Coordenadora de Ensino da FFCLRP-USP (1987-1988).

No mesmo grau de relevância e colaboração com o aprimoramento do ensino, foi o fundador e primeiro Coordenador do Programa de Pós-Graduação em Psicologia do Departamento de Psicologia da FFCLRP-USP, onde atuou como orientador de 1995 a 2001. Foi também fundador e coordenador do Curso de Psicologia da Universidade de Ribeirão Preto (UNAERP, 1998-2001). Árduo batalhador pela autonomia, desenvolvimento e fortalecimento da Psicologia como Ciência, foi grande incentivador para a criação e desenvolvimento do Programa de Pós-Graduação em Saúde Mental da Faculdade de Medicina de Ribeirão Preto (USP) e do Programa de Pós-Graduação em Psicologia (stricto sensu) da Universidade São Francisco, atualmente programas de excelência em suas áreas segundo a Coordenação de Aperfeiçoamento de Pessoal de Nível Superior (Capes). 
Em relação à carreira docente, atuou como professor nas disciplinas de graduação do Departamento de Psicologia da FFCLRP-USP e da FMRP-USP (19671998). Foi Professor colaborador da Faculdade de Filosofia, Ciências e Letras de Assis (Unesp) nos anos de 1972-1973. Foi Professor Colaborador do Instituto de Psicologia da USP (1985-1987).

Em relação à Pós-Graduação, atuou como professor e orientador credenciado no período de 1975 a 2000. Atuou no Programa de Pós-Graduação do Instituto de Psicologia da Universidade de São Paulo (IP-USP), no Programa de Pós-Graduação em Saúde Mental da Faculdade de Medicina de Ribeirão Preto-USP e no Programa de Pós-Graduação em Psicologia da Faculdade de Filosofia, Ciências e Letras de Ribeirão Preto-USP. Nesse último Programa de Pós-Graduação foi seu primeiro coordenador (1994-1997), como anteriormente apontado.

Além disso, propiciou intercâmbios entre professores dos Programas de Pós-Graduação em que era orientador credenciado e de várias instituições internacionais. Recebíamos na FFCLRP-USP professores convidados pelo Professor André Jacquemin, sempre com seu espírito de integração e de desenvolvimento dos setores de pesquisa e de atuação profissional, inicialmente num forte vínculo com a Sociedade de Psicologia de Ribeirão Preto (SPRP) e depois incentivando a pós-graduação, sobretudo no início do programa em Saúde Mental da FMRP-USP (a partir de 1991) e, mais tarde, na elaboração e participação no programa de Pós-Graduação em Psicologia da FFCLRP-USP (a partir de 1995). Com toda a clareza este convívio foi extremamente profícuo: Nina Rausch de Traubenberg (responsável pela Escola Francesa do Rorschach), George De Vos (com seus estudos sobre o Teste de Apercepção Temática em diferentes culturas), Jean-Marie Barthélémy, Zena Helman e Michel Wawrzyniak (com os trabalhos da Psicopatologia Fenômeno-Estrutural), Martin Achtnich e sua esposa Heidi Achtnich (com o Teste de Fotos de Profissões BBT), entre outros inúmeros pesquisadores internacionais vieram a Ribeirão Preto (SP) e deixaram marcas e sementes de campos de atuação em pesquisa científica. Isto sempre foi (e será) encantador, presentes ofertados pelo convívio com Professor André Jacquemin e por seus múltiplos contatos profissionais na Europa.

\section{Percurso de inovações e legados}

Em 1975, em harmonia com seus ideais científico-acadêmicos, André Jacquemin oficializou a criação do Centro de Pesquisas em Psicodiagnóstico (CPP) na FFCLRP-USP, o qual coordenou até seu afastamento em 2001. Seu objetivo sempre foi o fortalecimento da área da Avaliação Psicológica no Brasil, propiciando espaço e estímulo aos estudantes de graduação, pós-graduação e aprimoramento profissional para desenvolverem projetos de investigação científica de técnicas avaliativas, enfocando seus diferentes campos de aplicação. Atualmente, o CPP agrega pesquisadores de diversas linhas de pesquisa vinculados ao Departamento de Psicologia da FFCLRP-USP e outras instituições de ensino e pesquisa, que têm processos de avaliação psicológica em sua prática profissional, seja ela clínica ou de pesquisa, constituindo também um Grupo de Pesquisa registrado no Diretório de Grupos de Pesquisa do Conselho Nacional de Desenvolvimento Científico e Tecnológico (CNPq).

Nesse processo ainda criou e estruturou outro serviço de Extensão Universitária, um grande sonho do Professor André Jacquemin: o Centro de Orientação Psicopedagógica e de Informação para os Estudos (COPI). Foi elaborado e instituído no Campus USP de Ribeirão Preto no final do ano de 1989 e início de 1990. Cada passo de instalação deste projeto foi minuciosamente construído e demorado, mas comemorado em sua efetivação gradativa. Existe até hoje, remodelado, porém fiel aos objetivos de cuidados em saúde mental a discentes de graduação do campus universitário.

Seu histórico acadêmico e pessoal evidencia seu estilo engajado e empreendedor, inovador, sempre em busca do aprimoramento científico e fortalecimento de ideais coletivos dentro e fora da Universidade de São Paulo. E aplicando seu estilo respeitoso à diversidade, buscou agregar e fortalecer as diferentes formas do "pensar em Psicologia". Assim, participou da fundação e desenvolvimento de importantes associações científicas, como a Sociedade Brasileira de Psicologia (SBP, criada em 1971 em Ribeirão Preto) e a Associação Brasileira de Rorschach e Métodos Projetivos (ASBRo, criada em 1993 em Ribeirão Preto), sendo seu Presidente e membro diretor por várias gestões. Hoje, ambas essas Associações Científicas possuem reconhecimento internacional, como atesta, por exemplo, a parceria da ASBRo com as atividades da International Society of the Rorschach and Projective Methods (ISR).

Para que sejamos justos na avaliação de sua carreira (e também de seus contemporâneos) enquanto orientador nas atividades de pós-graduação, vale lembrar o contexto acadêmico da Universidade em que ele viveu. Até 1990 o acesso aos microcomputadores 
era ainda bastante restrito nas universidades brasileiras e a internet começou a surgir no Brasil em 1988. Assim, para os leitores da geração Y ou conseguintes, vale a pena lembrar que todos os trabalhos acadêmicos e documentos formais eram registrados caligraficamente ou em máquinas datilográficas, com centenas de horas de trabalho e outras muitas noites de retrabalho formal nesses textos. Tratava-se da época em que o tempo médio dos doutoramentos se aproximava dos oito a dez anos e os mestrados, em torno de cinco anos para seu desenvolvimento e conclusão. Assim, esse era o contexto dos números que apresentaremos a seguir e merecem ser compreendidos dentro da real grandeza de sua representação.

Em aproximadamente 30 anos atuando na graduação e pós-graduação, o professor André orientou 27 Dissertações de Mestrado, 14 Teses de Doutorado, quatro Monografias e 13 Iniciações Científicas. E seus indicadores de produção integram 51 artigos publicados em periódicos nacionais e internacionais, 133 trabalhos apresentados em eventos científicos, sete autorias de livros, sete capítulos de livros e cinco livros organizados. Quando se afastou dos trabalhos, por motivo de saúde, em 2001, estava em plena atividade acadêmica e funcional, embora formalmente aposentado na USP, a trabalhar a todo vapor em Universidade particular em Ribeirão Preto (CFP, 2004; Pasian, 2017).

Ao considerarmos que a Psicologia foi regulamentada como profissão no Brasil em 1962, é possível imaginar como se configurava a área da Avaliação Psicológica em nosso país quando Professor André iniciou seus trabalhos na FFCLRP-USP, no ano de 1967 e posteriores. Segundo Trinca (2001), as contribuições de André Jacquemin ao campo da Avaliação Psicológica no Brasil foram vastas e abrangentes. Abarcaram o campo do ensino, da pesquisa, construção e adaptação de instrumentos, além da aplicação clínica dos resultados nos mais diversos temas. Suas investigações científicas envolveram várias etapas do desenvolvimento, incluindo o idoso, o universitário, o imigrante, até quadros clínicos variados (asma, disfunções renais e diálise, obesidade, coronariopatias, transtornos psiquiátricos, entre outras), caminhando para a questão das escolhas profissionais de curso e carreiras. Segundo as reflexões de Trinca (2001):

Todos sabemos que ele nos ajudou a compreender melhor os métodos e os resultados na obtenção do conhecimento em Psicologia e que faz parte de uma geração de psicólogos brasileiros que modificou os rumos do diagnóstico psicológico, das técnicas projetivas e da própria forma de encarar a Psicologia. Mas o que é espantoso é a dimensão do plano de sua obra, a extensão e a profundidade dos assuntos. São de domínio e amplitude muito vastos. Encontramos nele uma personalidade multiforme, inquieta e indagadora, que se interessa pela pesquisa ampla e, simultaneamente, meticulosa [...] Ele nunca teve uma noção restrita, elementarista ou determinista da Ciência. Por isso, conseguiu manter uma atitude científica multifacetada, ampla e diversificada. Uma separação de tudo o que não constitui sólida base científica. Nele, esteve continuamente acesa a discussão dos problemas técnicos específicos, associada a uma consideração geral pelos fins. Isso o deixou transitar facilmente pelos meios intelectuais e acadêmicos, fazendo sentir sua personalidade inteligente, acolhedora e afável. [...] Uma inteligência excepcional que se alia a uma imensa capacidade de trabalho. Desse modo, a pesquisa [...] teve um impulso que ultrapassou as medidas das áreas de sua preferência, a fim de influenciar muitas outras áreas.

Cabe destacar aqui que, em 2001, ano do afastamento do Professor André das atividades de trabalho, houve uma proposta pouco comum na rotina universitária. Foi um convite do Professor Oswaldo Baffa Filho, na época Diretor da FFCLRP/USP, para desenvolvermos um evento em homenagem às contribuições do Professor André Jacquemin em nossa Faculdade. Não dava para deixar passar este momento da história. E o desejo foi tomando corpo em algumas reuniões, conversas de corredor e muitos, muitíssimos contatos, necessários diante da extensa rede de intercâmbio profissional do Professor André. Muitas pessoas participaram destes esforços na composição de sua homenagem, mas o objetivo só se concretizou porque juntamos, para além de nossas fortes diferenças, um projeto comum. Desta diversidade de contribuições resultou o Simpósio intitulado: "Prof. Dr. André Jacquemin: seu pioneirismo e contribuições científicas no Brasil", ocorrido em 14 de Novembro de 2001, com a marcante presença do Prof. Dr. Michel Wawrzyniak e do Prof. Dr. Danilo Rodrigues Silva, respectivamente pesquisadores da França e de Portugal. Também foi possível reunir, a muitíssimas mãos, um 
livro para homenagear Prof. Dr. André Jacquemin, composto a partir das memórias e das vivências de inúmeras pessoas que com ele puderam conviver no trabalho e na vida cotidiana. Intitulou-se: "André Jacquemin: uma homenagem", editado pela Vetor, Casa do Psicólogo e CETEPP, ao qual tomamos a liberdade de recomendar fortemente a leitura.

Com apreço ao conhecimento, sua personalidade curiosa e inquieta inspirava alunos e colegas para que o seguissem pelo caminho de suas hipóteses científicas. Sua habilidade em reunir bons pesquisadores, em identificar as questões de pesquisa emergentes em cada um de seus orientandos, em agregar verbas juntos às agências de fomento à pesquisa (Fundação de Amparo à Pesquisa do Estado de São Paulo - Fapesp, Capes, CNPq, Financiadora de Estudos e Projetos - Finep), constituíam a essência do primor e fervor pelo conhecimento que ele transmitia aos alunos em sala de aula.

Nessa mesma direção, era um árduo defensor do aprimoramento dos instrumentos de avaliação psicológica no Brasil e, para isso, participou das primeiras iniciativas nesse sentido em nosso país, buscando apoio na comunidade acadêmica e no Conselho Federal de Psicologia (CFP). Foram assim suas ativas presenças e coordenações nas Comissões de Avaliação Psicológica existentes nas décadas de 1980 e 1990 no CFP, até a criação do Sistema de Avaliação de Testes Psicológicos (Satepsi) em 2001.

Em 2017, após 16 anos de intensos e crônicos cuidados de saúde, Professor André partiu. Deixou ensinamentos até nesse processo de resistência pela vida, ao longo desse convívio. Cabe destacar um depoimento do Prof. Dr. William Barbosa Gomes (comunicação pessoal) nesse momento de sua passagem:

Associo-me com profunda tristeza às manifestações de pesar pelo falecimento do professor André Jacquemin. Tive o privilégio de compartilhar várias atividades acadêmicas com o estimado professor e ele sempre me impressionou pelo elevado senso ético e franca assertividade. Há muito sabíamos e lamentávamos as difíceis condições de saúde de Jacquemin, mas nos consolávamos lembrando da significativa liderança científica que exerceu nos programas de Psicologia da USP-RP, e na então Sociedade de Psicologia de Ribeirão Preto, hoje, nossa Sociedade Brasileira de Psicologia. Que a memória deste inesquecível mestre e pesquisador seja lembrada e preservada na história da Psicologia brasileira, em especial, na história da Psicologia USP-RP, onde foi um diferencial na pesquisa e ensino em avaliação psicológica, e na Sociedade Brasileira de Psicologia onde foi uma força ativa e determinada.

O pioneirismo, a seriedade, a humildade, a ética e o compromisso com a Psicologia (nos diferentes contextos de pesquisa, de ensino e de serviços de extensão à comunidade) são as marcas deste Professor, o que lhe conferiu várias homenagens dos alunos em seu percurso universitário.

"A vida é uma coletânea de momentos, vivências, pessoas, sentimentos, lugares e coisas que, juntos, acabam tecendo significados" (Okino, 2001). Esses significados ficam nas lembranças, algumas delas guardadas com carinho em algum lugar muito especial, dentro de nós.

A semente plantada pelo Professor André, como disse Josette (comunicação pessoal), sua esposa, foi plantada em nós. Em suas palavras: "E que ela seja cultivada, para germinar em todos os cantos e, com certeza, florescer e espalhar seus frutos. Dando continuidade ao seu trabalho, buscando aprender, aperfeiçoar e transmitir sempre. Sua presença será assim marcada, não importando a distância, que o fará sempre realizado e muito feliz".

Juntamo-nos a essa história e deixamos registrada nossa gratidão por seu compartilhar de vida e ensinamentos. Ao Mestre, com carinho, nossa sincera homenagem!

\section{Referências}

Alves, R. (1994). A alegria de ensinar (4a ed.). São Paulo, SP: Ars Poética.

Conselho Federal de Psicologia (2004). André Jacquemin. Psicologia: Ciência e Profissão, 24(1), 129. https://doi. org/10.1590/S1414-98932004000100014

Jacquemin, A. A. (1973). O Teste de Rorschach em crianças brasileiras: Pesquisa e atlas (Tese de doutorado). Instituto de Psicologia da Universidade de São Paulo, São Paulo, SP, Brasil.

Jacquemin, A. A. (1976). O Teste de Rorschach em crianças brasileiras: Pesquisa e atlas. São Paulo, SP: Vetor. 
Okino, E.T.K. (2001). E, para encerrar.... In: Okino, E. T. K., Pasian, S. R.; Petean, E. B. L., \& Santos, L.A. (2001). André Jacquemin: Uma homenagem (p. 118). São Paulo, SP: Vetor.

Okino, E. T. K.; Pasian, S. R.; Petean, E. B. L., \& Santos, L.A. (2001). André Jacquemin: Uma homenagem. São Paulo, SP: Vetor.

Pasian, S. R. (2017). André Jacquemin: Uma homenagem. Reunião Anual de Psicologia da Sociedade Brasileira de Psicologia (Pôster), São Paulo, SP, 48.

Trinca, W. (2001). Homenagem a André Jacquemin. In: Okino, E. T. K., Pasian, S. R.; Petean, E. B. L., \& Santos, L.A. (2001). André Jacquemin: Uma homenagem (pp. 58-60). São Paulo, SP: Vetor.

\section{Sonia Regina Pasian}

Professora do Departamento de Psicologia da Faculdade de Filosofia, Ciências e Letras de Ribeirão Preto da Universidade de São Paulo. Ribeirão Preto - SP. Brasil.

E-mail: srpasian@ffclrp.usp.br

\section{Erika Tiemi Kato Okino}

Doutora em Psicologia pelo Departamento de Psicologia da Faculdade de Filosofia, Ciências e Letras de Ribeirão Preto da Universidade de São Paulo. Ribeirão Preto - SP. Brasil.

E-mail: erikatko@ffclrp.usp.br

Endereço para envio de correspondência:

Av. Bandeirantes, 3900 - Monte Alegre. CEP: 14.040-901.

Ribeirão Preto - SP. Brasil.

Recebido: 20/07/2018

Aprovado: 07/08/2018

Received: 07/20/2018

Approved: 08/07/2018

Recibido: 20/07/2018

Aceptado: 07/08/2018

Como citar: Pasian, S. R., \& Okino, E. T. K. (2018). Professor André Jacquemin: Reconhecimento a sua trajetória profissional. Psicologia: Ciência e Profissão, 38(n.spe), 207-213. https://doi.org/10.1590/1982-3703000208761

How to cite: Pasian, S. R., \& Okino, E. T. K. (2018). Professor André Jacquemin: Recognition of his professional trajectory. Psicologia: Ciência e Profissão, 38(n.spe), 207-213. https://doi.org/10.1590/1982-3703000208761

Cómo citar: Pasian, S. R., \& Okino, E. T. K. (2018). Profesor André Jacquemin: Reconocimiento a su trayectoria profesional. Psicologia: Ciência e Profissão, 38(n.spe), 207-213. https://doi.org/10.1590/1982-3703000208761 